\title{
MISERICORDIAE VULTUS Menelisik Bulla Pemakluman Yubileum Luar Biasa Kerahiman
}

\author{
Sihol Situmorang*
}

\begin{abstract}
Abstrak
Tatkala dunia diterpa oleh berbagai kekerasan yang mengakibatkan rentetan tragedi dan penderitaan, Paus Fransiskus menetapkan Yubileum Luar Biasa Kerahiman. Paus yakin, bahwa kekerasan hanya dapat diretas bila manusia menjadikan belas kasih sebagai spirit dan landasan hidup, dalam berpikir maupun bertindak. Masa depan yang lebih baik, damai dan bersaudara dapat dicapai bila manusia belajar hidup menurut citranya yang sejati, yakni Allah, yang telah menciptakan manusia menurut gambar dan rupa-Nya sendiri. Citra Allah tidak lain adalah belas kasih. Seruan untuk berbelas kasih seperti Bapa merupakan ajakan untuk menghidupi jati diri manusia seperti tatkala ia diciptakan. Oleh dosa, manusia kehilangan gambaran diri Allah dalam dirinya. Yesus datang dan menjadi manusia untuk memulihkan citra manusia dan mewujudkan belas kasih Allah. Umat beriman, dengan bercermin pada Yesus dan merenungkan Injil, diajak menjadi insan yang berberlas kasih dan murah hati, sebagaimana tertuang dalam motto yubileum luar biasa ini, yakni Misericordes sicut Pater.
\end{abstract}

Kata-kata kunci: Allah, Yesus Kristus, Injil, Gereja, Fransiskus, yubileum, penderitaan, kerahiman, kemurahan, belas kasih, rekonsiliasi, pintu suci.

\section{Pendahuluan}

Tahun Kerahiman, yang dimaklumkan oleh Paus Fransiskus tanggal 11 April 2015 dengan bulla Misercordiae Vultus, memiliki arti yang istimewa khususnya saat dunia kita dilanda oleh tragedi kemanusiaan dan berbagai kekerasan pada lingkup lokal, nasional atau global. Kekerasan dengan berbagai modus telah menelan korban dan kerugian yang tidak terhitung jumlahnya, baik materi maupun moral-psikologis. Misteri

* Sihol Situmorang, Lisensiat dalam bidang Teologi Patristik; lulusan Universitas Lateran, Italia; Dosen Teologi pada Fakultas Filsafat Unika St. Thomas, Sumatera Utara. 
dosa serta akibat-akibatnya semakin terasa luas dan mendalam, tidak bisa dijelaskan dengan mudah, apalagi diatasi oleh kekuatan manusia.

Mata rantai kekerasan ini, sebelum menjadi bencana bola salju yang tidak terkontrol, hanya mungkin diretas bila manusia, secara personal maupun sosial, menjadikan misericordia sebagai modus vivendi atau way of life. Hanya dengan menghidupi kerahiman, kemurahan hati dan belas kasih, kerapuhan dan luka-luka kehidupan dapat disembuhkan. Iman akan Yesus Kristus, wajah sempurna belas kasih Allah, mendorong Gereja untuk makin gigih memperjuangkan dan menata hidup yang lebih bermurah hati, bersaudara, adil dan damai. Dengan demikian manusia masih dapat berharap akan dunia yang lebih baik, indah, damai dan bersaudara. ${ }^{1}$

\section{Sejarah Yubileum}

Perayaan tahun suci atau yang lebih dikenal sebagai tahun yubileum bukanlah sesuatu yang baru dalam tradisi Gereja. Yubileum berasal dari bahasa Ibrani Yovel, yang berarti tanduk biri-biri jantan. Tanduk itu ditiup untuk menandai tahun ke-50, tahun setelah kelipatan angka tujuh (7), yang diyakini sebagai bilangan sempurna. Praktek yubileum didasarkan pada tradisi biblis, khususnya Perjanjian Lama, "Kamu harus menguduskan tahun kelima puluh, dan memaklumkan kebebasan di negeri itu bagi segenap penduduknya. Itulah menjadi tahun Yobel bagimu," (Im 25:10). Ide yang terkandung di dalam tahun Yobel ini adalah memutus siklus hidup harian demi membarui relasi manusia dengan Pencipta. Pembaruan relasi dengan Allah memiliki implikasi konkrit terhadap relasi dengan sesama manusia. Apa saja yang dihasilkan oleh bumi pada tahun ini dibagikan di antara orang yang sangat membutuhkan, dan utang pun dihapuskan. Di dalam tahun khusus ini juga terdapat ide ekologis. Manusia tidak boleh terusmenerus mengerjakan ladang untuk memenuhi kebutuhannya. Ada

1 http://www.usccb.org/beliefs-and-teachings/how-we-teach/newevangelization/jubilee-of-mercy/frequently-asked-questions-about-the-jubileeof-mercy.cfm; Joseph Lobo, "Mercy and Justice: The Warp and Woof of Human Life" dalam Vidyajyoti Journal of Theological Reflection (VJTR) 80/4 April 2016, hlm. 27; Kuriakose Poovathumkudy, "Holy Year of Mercy: An Exploratory Study of Misericordiae Vultus" dalam Vidyajyoti Journal of Theological Reflection (VJTR) 80/2 February 2016, hlm. 12. 
aturan ilahi yang harus ditaati, sebab bumi adalah milik Tuhan (bdk. Im $25: 23) .^{2}$

Inti Yubileum orang Ibrani ialah penantian akan kedatangan Mesias Pembebas yang penuh belas kasih, yang juga membawa kebebasan bagi semua bangsa. Kedatangan-Nya merupakan pemenuhan nubuat Yesaya, "Roh Tuhan ada padaku... Dia telah mengutus aku untuk membawa kabar gembira bagi orang miskin," (Yes 61:1-3). Tahun Yubileum ini dimaknai sebagai tahun pengampunan dan peringatan akan penyelenggaraan dan belas kasih Allah. Pengkhususan satu tahun untuk tujuan ini diharapkan membuat komunitas kembali pada relasi yang benar dan baik dengan sesama dan dengan Allah. Ketika Gereja Katolik mengadopsi praktek tahun yubileum ini, tema belas kasih, pengampunan dan solidaritas tadi tetap ada di dalamnya. ${ }^{3}$

Yubileum pertama dimaklumkan oleh Paus Bonifasius VIII pada tanggal 22 Februari 1300 dengan bulla Antiquorum fida relatio. Dalam yubileum ini ditekankan perlunya gerakan spiritualitas dan pengampunan untuk menghadapi situasi pada masa itu yang dilanda kekerasan dan kebencian. Sampai tahun 1470, Yubileum dirayakan setiap 100 atau 50 tahun. Sesudah itu yubileum dirayakan setiap 25 tahun, agar setiap generasi bisa mengalami setidaknya satu tahun suci. Kekecualian terjadi pada tahun 1850 ketika Paus Pius IX berada di pembuangan. Karena alasan dan tujuan tertentu, Paus dapat mengundangkan yubileum agung di luar siklus normal. Tahun 1933 dan 1983 dirayakan sebagai Yubileum Luar Biasa Karya Penyelamatan Kristus (Jubilee of Redemption). Setiap tahun yubileum dimaklumkan dengan Bulla dan ditandai dengan pembukaan Pintu Suci. ${ }^{4}$

2 http://www.usccb.org/beliefs-and-teachings/how-we-teach/newevangelization/jubilee-of-mercy/frequently-asked-questions-about-the-jubileeof-mercy.cfm; https://cvcomment.org/2015/12/08/what-you-need-to-knowabout-the-jubilee-of-mercy/

3 https://cvcomment.org/2015/12/08/what-you-need-to-know-aboutthe-jubilee-of-mercy/

4 Kuriakose Poovathumkudy, "Holy Year of Mercy...", hlm. 12; http:/ / www.usccb.org/beliefs-and-teachings/how-we-teach/newevangelization/jubilee-of-mercy/frequently-asked-questions-about-the-jubileeof-mercy.cfm; http://www.orlandodiocese.org/e-scroll/archive/presentationof-the-extraordinary-jubilee-of-mercy-2/;

https://cvcomment.org/2015/12/08/what-you-need-to-know-about-the- 


\section{Yubileum Istimewa Kerahiman}

Dalam Perayaan Tobat di Basilika Santo Petrus tanggal 13 Maret 2015, Paus Fransiskus mengumumkan keputusan untuk merayakan suatu yubileum istimewa, "Saudara-saudari tercinta, sudah sering saya pikirkan bagaimana Gereja dapat lebih jelas menunjukkan panggilannya untuk menjadi saksi kerahiman. Ini merupakan perjalanan yang mulai dengan pertobatan rohani. Kita harus menjalaninya. Sebab itu, saya memutuskan untuk mengumumkan suatu Yubileum Istimewa yang berpusat pada kerahiman Allah, yakni Tahun Suci Kerahiman. Tahun rahmat ini ingin kita hayati dalam terang sabda Tuhan: Hendaklah kamu murah hati, sama seperti Bapamu adalah murah hati (Luk 6:36)." ${ }^{5}$

Alasan penetapan tahun luar biasa ini ialah perubahan mendasar yang tengah terjadi zaman ini. Gereja dipanggil untuk mempersembahkan kontribusi khusus agar tanda-tanda kehadiran dan kedekatan Allah makin tampak. Paus menegaskan bahwa berbelas kasih merupakan peran sentral Gereja, sebab Yesus sendiri menjadikan belas kasih sebagai pokok utama pelayanan-Nya. Gereja dipanggil untuk mewartakan karunia belas kasih.6 "Ini merupakan tahun rahmat yang istimewa, tahun pengampunan dosa dan hukuman yang diakibatkannya, suatu tahun rekonsialiasi bagi pihak-pihak yang bertikai," kata Paus

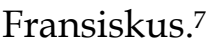

jubilee-of-mercy/; T. Krispurwana Cahyadi, Kemurahan Hati: Wajah AllahKesksian Gereja, (Yogyakarta: Kanisius, 2016), hlm. 13-15.

5 http://ncronline.org/news/vatican/proclaiming-jubilee-francisenvisions-non-judging-non-condemning-church

$$
6
$$

ttps://w2.vatican.va/content/francesco/en/audiences/2015/documents/pap a-francesco_20151209_udienza-generale.html; Paus Fransiskus, Misericordiae Vultus (Wajah Kerajhiman), Bulla Pemberitahuan Yubileum Luar Biasa Kerahiman, (Diterjemahkan oleh F.X. Adisusanto, SJ), Dokpen KWI no 99B: Jakarta, Februari 2016, no. 2. Dokumen ini selanjutnya disingkat MV dan diikuti nomor.

7 http://www.americamagazine.org/content/dispatches/pope-francisannounces-jubilee-year-mercy 


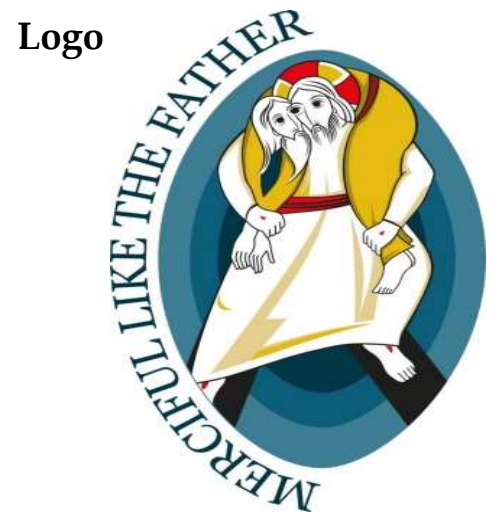

Logo menampilkan summa theologiae tema kerahiman dan motto misericordes sicut Pater. Logo ini dirancang oleh P. Marko I. Rupnik SJ. Di sana diperlihatkan Yesus tengah memanggul seseorang pada bahunya. Sejak Gereja awal gambaran ini sangat penting untuk memperlihatkan Putra Allah yang memanggul di bahu-Nya jiwa yang hilang. Logo dibuat sedemikian rupa untuk mengungkapkan cara paling dalam bagaimana Gembala Baik menyentuh daging manusiawi dan melakukan itu dengan cinta yang dapat mengubah hidup seseorang. Ketika Tuhan menerima kemanusiaan atas diri-Nya, mata-Nya bersatu dengan mata manusia. Tuhan sungguh merasakan kemanusiaan itu dan mencintainya. Kristus melihat dengan mata Adam dan Adam melihat dengan mata Kristus. Setiap orang menemukan dalam Kristus - Adam yang baru - kemanusiaan baru dan masa depan baru, di mana cinta Allah menjadi nyata. ${ }^{8}$

Gambaran diletakkan dalam mandorla, yakni belahan buah badam. Mandorla merupakan ikon yang dipakai oleh Gereja purba dan abad pertengahan untuk menggambarkan koeksistensi kodrat Kristus: ilahi dan manusiawi. Latar belakang logo tersebut berupa tiga oval konsentris. Makin ke luar, warna oval itu makin terang untuk menggambarkan tindakan Kristus yang membawa manusia keluar dari kegelapan dosa dan kematian. Warna yang makin gelap juga melukiskan misteri cinta Bapa yang tidak terselami, cinta yang mengampuni semuanya. ${ }^{9}$

8 http://www.im.va/content/gdm/en/giubileo/logo.html; Gabriel Possenti Sindunata, "Bermurah hati terhadap anak" dalam Utusan 07/Tahun Ke-66, Juli 2016, hlm. 2.

9 http://www.im.va/content/gdm/en/giubileo/logo.html; Gabriel Possenti Sindunata, "Bermurah hati terhadap anak" ..., hlm. 2. 


\section{Misericordia}

Misericordia merupakan bahasa Latin klasik, sebagai perpaduan dari kata miserum dan cor. Kata miserum berarti penderitaan lahir-batin, keadaan luar biasa malang, miskin dan kecil, yang mengancam eksistensi seseorang sehingga terpaksa hidup di ambang batas hidup manusia. Orang yang mengalami penderitaan ekstrim tersebut memohon belas kasih, rasa iba, simpati, kepedulian dan compassion (turut merasakan penderitaan). Kata cor (hati) menunjuk pada pusat jati diri. Hati adalah tempat bagi perasaan dan paham tentang kegembiraan, penderitaan, cinta, kenteraman atau kegelisahan. Hati tidak dapat dimasuki dan dinilai oleh akal budi. Ketika menemukan miserum, cor tidak bertindak sebagai hakim tetapi mendekati lalu membakar dan menghancurkannya. Dalam bahasa Latin disebut urere. Perpaduan miserum dan cor membentuk misericordia; sebuah tatapan penuh cinta dan bela rasa. Misericordia turun dengan bebas untuk menyelamatkan dan menghapuskan penderitaan dengan sepenuh hati. Belas kasih tersebut lahir, hidup dan memberi nafkah serta menyatakan diri melalui pengampunan dan afeksi. ${ }^{10}$

Dalam Perjanjian Baru, misericordia diterjemahkan eleos (Yunani), yang merupakan terjemahan hésèd dan rahamin dalam bahasa Ibrani. Hésèd termasuk salah satu kata yang paling indah dalam Kitab Suci untuk menjelaskan kesetiaan dan belas kasih Allah. Hésèd diterjemahkan dengan cinta, kesetiaan dalam cinta atau kesetiaan cinta Allah bagi manusia. Rahamin berasal dari kata rahem atau rahim, yaitu unsur hakiki dalam tubuh perempuan, di mana akar kehidupan ditanam, dirawat dan ditumbuhkan sampai menjadi anak manusia yang siap dilahirkan. Rahamin menunjuk kepada hésèd yang penuh perasaan, kasih ibu kepada anak yang dikandungnya, cinta total tanpa syarat yang timbul dari kedalaman hati. Misericorida (kerahiman) berarti pembukaan hati bagi penderitaan (miseria) atau hati yang tergerak oleh penderitaan atau belas kasih. ${ }^{11}$

10 Pontifical Council for the Promotion of the New Evangelization, Mercy in the Fathers of the Church, (United States of America: Promotion of the New Evangelization, 2015), hlm. 14-16.

11 MV 5; Monica Maria Meifung, "Memaknai Tahun Kerahiman" dalam Rohani No.2/Tahun ke-63/Februari 2016, hlm. 11; Benitius Brevoort, "Yubileum Istimewa Kerahiman" dalam Persaudaraan (Majalah Ordo Kapusin Propinsi Medan), No. 2/XIV/April-Juni 2016, hlm. 10-11; Y. Aristanto HS, "Pastoral Keluarga dalam Terang Belas Kasih Allah, Mengungkapkan wajah belaskasih 


\section{Yesus, Wajah Kerahiman Allah}

Kerahiman dan belas kasih mewahyukan misteri Tritunggal. Kerahiman Allah itu hidup, tampak dan mencapai puncaknya dalam diri Yesus dari Nazareth, wajah kerahiman Allah. ${ }^{12}$ Menurut Paus Fransiskus, kerahiman adalah nama Allah (The Name of God is Mercy), karena tanpa kerahiman, Allah berhenti menjadi Allah, dan kehidupan tidak akan berjalan ketika Allah berhenti menjadi Allah. Kerahiman adalah tindakan terakhir dan tertinggi dari pendekatan Allah kepada manusia. Kerahiman merupakan jalan yang menyatukan Allah dan manusia. Kita dicintai selama-lamanya melewati batas dosa, kelemahan dan kerapuhan kita. ${ }^{13}$ Terkagum-kagum pada kerahiman Allah Tritunggal, Paus menghindari rumus-rumus kaku dan kalimat berbau definisi. Paus mengajak umat beriman untuk memandang misteri kerahiman dan belas kasih ini sebagai sumber kegembiraan, kesejahteraan dan damai. Paus berharap agar pada tahun kerahiman ini kita menjadi tanda dan saksi yang lebih efektif bagi perbuatan Allah dalam kehidupan kita. ${ }^{14}$

Kerahiman adalah tema utama Kitab Suci, Perjanjian Lama dan Injil. Melalui yubileum istimewa ini, Paus hendak memaklumkan kembali isi pokok Kitab Suci, di mana kerahiman merupakan hakikat Allah. Allah mewahyukan kemahakuasaan-Nya terutama lewat kerahiman dan pengampunan. Allah hadir dalam sejarah manusia sebagai yang penuh kerahiman, perhatian dan belas kasih. Ajaran Yesus dalam aneka perumpamaan memberi petunjuk bahwa kerahiman bukan hanya mengacu pada tindakan Allah Bapa, melainkan juga sebagai sebuah kriteria untuk memastikan siapa anak-anak Allah yang sejati. ${ }^{15}$

Allah dalam Pastoral Keluarga", dalam Komisi Keluarga Konferensi Waligereja Indonesia, Keluarga (Bulletin Sarana dan Wahana Komunikasi Pastoral Keluarga), No. 1/Januari-April 2016, hlm. 25; P Ken Barker, His Name is Mercy: Belas Kasih adalah Sumber Pemgampunan (Judul Asli: His Name is Mercy, diterjemahkan oleh Ernest Maryanto), (Jakarta: Marian Centre, 2013), hlm. 9-11.

12 MV no.1; Y. Aristanto HS, "Pastoral Keluarga ...", hlm. 28.

${ }^{13}$ MV no. 2; Kuriakose Poovathumkudy, "Holy Year of Mercy...", hlm.

14.

14 MV 3.

15 MV no.7,8,9; Monica Maria Meifung, "Memaknai Tahun Kerahiman", hlm. 13; Benitius Brevoort, "Yubileum Istimewa Kerahiman"... hlm. 11; Gabriel Possenti Sindunata, "Tergerak oleh Belas Kasih" dalam Utusan No. 03/Tahun ke-66/Maret 2016, hlm. 2-3; Kuriakose Poovathumkudy, "Holy Year of Mercy...", hlm. 14-15. 


\section{Gereja, Sakramen Kerahiman Allah}

Merayakan Tahun Kerahiman Allah berarti memasuki secara istimewa dimensi feminitas cinta Allah dan menerima kehangatan kasih keibuan Gereja yang adalah sakramen kerahiman Allah. Penetapan tahun kerahiman merupakan suatu cara untuk mempertegas perutusan Gereja. Paus ingin agar melalui yubileum ini, Gereja makin sadar bahwa kerahiman adalah esensi dari pewartaan tentang Allah. Identitas dan panggilan Gereja yang paling dalam adalah mewartakan suka cita Injil dan menjadi tanda nyata dan sarana kerahiman Allah. Kerahiman Allah bukanlah sebatas sebuah devosi, tetapi dasar dan pola hidup Gereja. Gereja dipanggil menjadi rumah Bapa dengan pintu-pintu yang selalu terbuka lebar, di mana semua orang merasa diterima, dicintai dan diampuni. Gereja hendaknya menjadi ahli dalam belas kasih dan pakar kemurahan hati.16 "Saya yakin bahwa seluruh Gereja pada yubileum ini dapat menemukan kembali kegembiraan dan membuat belas kasih Allah berbuah. Dengan belas kasih itu kita dipanggil untuk memberi penghiburan bagi setiap pria dan wanita di masa kita ini," ujar Paus Fransiskus. ${ }^{17}$

Paus Fransiskus menandaskan bahwa kerahiman harus menjadi kriterium kredibilitas Gereja. Hal itu tampak dalam cinta yang ia perlihatkan dengan penuh kerahiman dan bela rasa. Gereja harus menjadi teladan pengampunan. Setiap kotbah dan kesaksian Gereja mesti dilengkapi dengan belas kasih. Tanpa itu, hidup menjadi sia-sia dan mandul. Paus menandaskan, "Waktunya sudah tiba bagi Gereja untuk menerima ajakan berbelas kasih kembali. Inilah saatnya kembali ke basis dan menanggung kelemahan serta perjuangan saudara-saudari kita. Belas kasihan adalah kekuatan yang membangunkan kita kembali pada hidup baru dan menanamkan dalam diri kita keberanian untuk memandang masa depan dengan harapan."18

16 Monica Maria Meifung, "Memaknai Tahun Kerahiman Allah" dalam Rohani no 2/Tahun ke-63/Februari 2016, hlm. 13; Benitius Brevoort, "Yubileum Istimewa Kerahiman" ".., hlm. 14-16.

$17 \mathrm{http}: / /$ ncronline.org/news/vatican/francis-announces-new-globaljubilee-holy-year-mercy; http://www.orlandodiocese.org/escroll/archive/ presentation-of-the-extraordinary-jubilee-of-mercy-2/

${ }^{18} \mathrm{MV}$ no. 10. 
Gereja menghayati kehidupan yang otentik apa bila mengakui dan memaklumkan belas kasihan, sifat yang paling menakjubkan dari Sang Pencipta dan Penebus, dan apa bila Gereja membawa manusia makin dekat ke sumber belas kasihan Sang Juru Selamat.19 Bila orang tidak menemukan dalam Gereja cinta yang penuh kerahiman, maka mereka tidak akan mengenal Gereja sebagai tubuh Kristus di dunia. Paus mengingatkan bahwa Gereja dipanggil pertama-tama untuk menjadi saksi yang pantas dipercaya tentang kerahiman dengan mengakui dan menghayati kerahiman sebagai intisari pewahyuan Yesus. ${ }^{20}$

\section{Pengampunan-Rekonsiliasi, Amal Belas Kasih dan Dialog}

Peziarahan menuju pintu suci bertujuan untuk memperoleh kerahiman dan belas kasih Allah. Peziarahan itu kiranya mendorong lahirnya pertobatan. Mengalami belas kasih, kerahiman dan pengampunan dari Allah menjadi motivasi bagi kita untuk bermurah hati seperti Bapa adalah murah hati. Paus Fransiskus mengajak umat beriman menempuh langkah-langkah peziarahan untuk mencapai tujuan tadi, yakni agar kita tidak menghakimi dan menghukum, melainkan mengampuni, karena kitalah yang pertama-tama mengalami kerahiman Allah. ${ }^{21}$ Paus berharap bahwa pada tahun kerahiman ini umat dapat merasakan anugerah pengampunan, rekonsiliasi dan indulgensi. Untuk itu akan diutus Missionaris Kerahiman, yakni imam-imam yang sabar dan memahami kerapuhan manusia dan siap untuk mengungkapkan keramahan yang penuh cinta dari Gembala Baik dalam khotbah dan Sakramen Pengakuan.22

Selama yubileum ini, orang-orang kristiani diajak untuk merefleksikan karya belas kasih jasmani dan rohani. Amal belas kasih ini merupakan cara membangkitkan kesadaran kita yang kerap tumpul sekaligus menjadi pintu masuk ke dalam inti Injil, di mana orang-orang miskin memperoleh pengalaman istimewa akan kerahiman Allah. Dengan beramal kasih, kita ambil bagian dalam tugas perutusan Kristus untuk mewujudkan tahun rahmat, tahun pembebasan atau tahun kerahiman

\footnotetext{
${ }^{19}$ MV no. 11.

${ }^{20}$ MV no. 12; Kuriakose Poovathumkudy, "Holy Year of Mercy...", hlm. 16-17.

${ }^{21}$ MV no. 13-14.

22 MV no. 17-22; http://archomaha.org/wpcontent/uploads/2015/11/Frequently_AskedQuestionsRegarding_the_Jubilee_ of_Mercy.pdf
} 
Tuhan (Yes 61:1-2).23 Paus juga berharap kiranya dalam tahun yubileum ini kerahiman terwujud dalam relasi dengan pemeluk agama Yahudi dan Islam untuk memperteguh dialog dan menemukan jalan untuk mengatasi kesulitan dalam ranah publik. ${ }^{24}$

\section{Pintu Suci}

Salah satu unsur pokok yubileum adalah Pintu Suci yang berkaitan dengan peziarahan. Peziarahan bertujuan untuk mendekatkan diri pada Allah dan menemukan saat-saat berahmat dan pembaruan spiritual. Belas kasih Allah dilambangkan dengan pintu yang terbuka menyambut setiap orang ke dalam cinta Allah yang penuh belas kasih. Gereja melambangkan Rumah Tuhan, dan Yesus Kristus adalah pintu bagi manusia menuju cinta Bapa. Ketika pintu suci dibuka pada awal tahun kerahiman, pintu itu menjadi pintu belas kasih. Melalui pintu suci itu mereka yang masuk akan mengalami cinta Allah yang menghibur, mengampuni dan menumbuhkan harapan. Paus Fransiskus menghendaki supaya yubileum ini dirayakan baik di Roma maupun di Gereja-gereja lokal. Mengingat nilai spiritual yang dilambangkan oleh pintu suci, maka Paus Fransiskus menetapkan agar, sesuai dengan kebijakan uskup setempat, pintu yang sama dapat dibuka pada setiap tempat suci yang dikunjungi banyak peziarah. ${ }^{25}$ Inilah untuk pertama kali dalam tradisi yubileum, setiap Keuskupan diberi kesempatan membuka Pintu Suci atau Pintu Kerahiman di Gereja Katedral atau Gereja-gereja yang mempunyai arti khusus atau tempat ziarah. ${ }^{26}$

Paus Fransiskus memberi simbolisme baru pada perayaan yubileum ini dengan lebih awal membuka Pintu Suci Katedral Bangui, Republik Afrika Tengah, negeri yang bertahun-tahun lamanya menderita akibat perang, kebencian, salah paham dan hilangnya damai. Tujuannya ialah untuk memperlihatkan bahwa kawasan yang ditandai dengan kekerasan, kemiskinan, perpecahan dan ketidakadilan adalah kawasan yang sungguh membutuhkan belas kasih dan kerahiman Allah yang senantiasa berada di pihak kaum yang terpinggirkan. Paus menegaskan bahwa di tengah situasi dunia dewasa ini, kita perlu berdoa dan

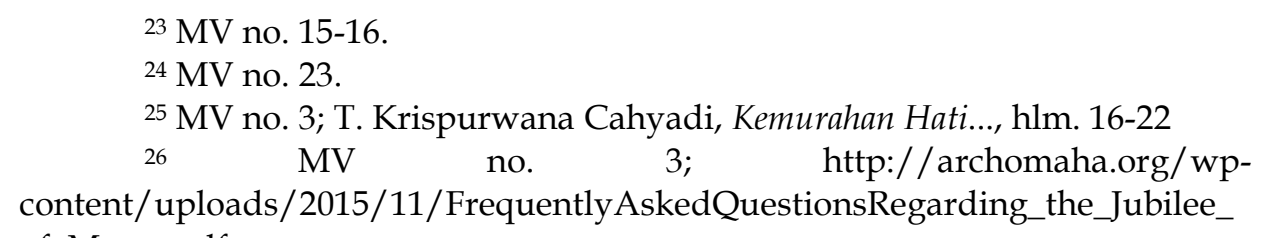
content/uploads/2015/11/FrequentlyAskedQuestionsRegarding_the_Jubilee_ of_Mercy.pdf 
memperjuangkan perdamaian, kemurahan hati, rekonsiliasi, pengampunan dan kasih. ${ }^{27}$

Dalam audiensi mingguan tanggal 18 November, Paus Fransiskus menjelaskan simbolisme yang ia sebut pintu kerahiman Tuhan, pintu yang senantiasa terbuka bagi semua yang mengetuk dan mau bertemu dengan Yesus. Pintu itu adalah Kristus sendiri (Yoh 10:9). Paus menegaskan bahwa pintu berguna untuk melindungi, bukan untuk menolak, dan karena itu perlu diketuk. Paus mengingatkan betapa penting sering membuka pintu untuk melihat apakah ada orang yang menanti di luar, yang mungkin tidak memiliki daya atau keberanian untuk mengetuk. Tahun Yubileum mengingatkan kita akan pintu besar kerahiman Allah, tetapi juga pintu-pintu kecil gereja kita, agar tetap terbuka kepada Tuhan atau untuk membiarkan Tuhan keluar, sebab sering menjadi tahanan pemikiran, keegoisan dan lain-lain. ${ }^{28}$

“Berjalan melalui Pintu Suci berarti menemukan kembali belas kasih tak terbatas dari Bapa yang menerima semua orang. Dan Dia sendiri keluar untuk mencari setiap orang. Ini merupakan tahun ketika kita akan bertumbuh dengan lebih yakin terhadap belas kasih Tuhan," kata Paus Fransiskus dalam khotbah pada misa pembukaan pintu suci pada tanggal 8 Desember 2105. ${ }^{29}$

\section{Penutup}

Kemurahan hati atau belas kasih merupakan intisari hidup di dalam Gereja dan dunia. Tidak heran kalau yubileum ini dicetuskan pada tanggal 13 Maret 2015, peringatan pemilihan Kardinal Bergolio, yang memiliki motto miserando atque eligendo, menjadi Paus. Yubileum ini juga menandai 50 tahun penutupan Konsili Vatikan II, konsili yang ditandai dengan nada kerahiman baru dari Allah bagi dunia modern. ${ }^{30}$ Yubileum ini sungguh tidak diduga, bahkan mengejutkan, khususnya mereka yang mahir dalam teologi dan Kitab Suci. Tema kerahiman yang

27 https://cvcomment.org/2015/12/08/what-you-need-to-knowabout-the-jubilee-of-mercy/; T. Krispurwana Cahyadi, Kemurahan Hati..., hlm. 16-17.

28 https://cvcomment.org/2015/12/08/what-you-need-to-knowabout-the-jubilee-of-mercy/

29

https://w2.vatican.va/content/francesco/en/homilies/2015/documents/papa -francesco_20151208_giubileo-omelia-apertura.html

${ }^{30}$ Kuriakose Poovathumkudy, "Holy Year of Mercy...", hlm. 12. 
dibahas dengan jelas dan rinci oleh Paus Yohanes Paulus II dalam ensiklik Dives in Misericordia umumnya diterima sebagai ulasan teologis yang menarik, tetapi kemudian ditaruh di laci meja. Paus yang sama lima belas tahun lalu menetapkan Hari Minggu Paskah II sebagai Minggu Kerahiman, namun belum berhasil menghantar para petugas pastoral kepada keyakinan bahwa kerahiman dan belas kasihan Allah merupakan intisari hidup Gereja. ${ }^{31}$

Bulla Misericordiae Vultus tergolong dokumen yang singkat, terdiri dari sekitar 9500 kata, dibagi dalam 25 nomor. Nada dan pendekatan sangat personal, intuitif dan membuka wawasan. Kendati singkat, namun dokumen ini sangat kaya secara teologis dan pastoral, dan tidak banyak menggunakan jargon teologis. Dalam dokumen ini Paus mengingatkan manusia akan kerapuhan dan kerentanannya, terutama kebutuhan akan kerahiman. ${ }^{32}$

Kendati Tahun Suci Kerahiman ditutup pada tanggal 20 November 2016, pada Hari Raya Tuhan Kita Yesus Kristus Raja Semesta Alam, hal itu tidak berarti bahwa Gereja sudah boleh berhenti menjadi sakramen kerahiman. Paus Fransiskus menyadarkan bahwa menjadi berbelas kasih adalah essensi dan jati diri Gereja. Gereja yang berhenti menjadi rahamin adalah Gereja yang kehilangan orientasi dan jati diri. Gereja mesti tetap menjadi penampakan karya belas kasih dan kerahiman Allah. Demikian kehadiran Gereja akan semakin dirasakan dan diuji kesetiaannya sebagai sacramentum salutis dan pengantin Kristus, yang adalah wajah sempurna belas kasih dan kerahiman Allah.

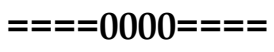

${ }^{31}$ Stefan Leks, "Kerahiman Allah, Intisari Hidup Gereja" dalam Hidup Katolik.com, Rabu, 16 Desember 2015, pkl. 12:08.

${ }^{32}$ Kuriakose Poovathumkudy, "Holy Year of Mercy...", hlm. 13. 
Sihol Situmorang, Misericordiae Vultus

\section{DAFTAR PUSTAKA}

Barker, P Ken, His Name is Mercy: Belas Kasih adalah Sumber Pengampunan. (Judul asli: His Name is Mercy, diterjemahkan oleh Ernest Maryanto), Jakarta: Marian Centre Indonesia, 2013.

Brevoort, Benitius., "Yubileum Istimewa Kerahiman" dalam Persaudaraan (Majalah Ordo Kapusin Propinsi Medan), no. 2/XIV/April-Juni 2016, hlm. 9-22.

Cahyadi, T. Krispurwana., Kemurahan Hati: Wajah Allah-Kesksian Gereja. Yogyakarta: Kanisius, 2016.

Fransiskus., Misericordiae Vultus (Wajah Kerahiman), Bulla Pemberitahuan Yubileum Luar Biasa Kerahiman, (Diterjemahkan oleh F.X. Adisusanto, SJ). Jakarta: Dokpen KWI, Februari 2016.

H.S, Y. Aristanto., "Pastoral Keluarga dalam Terang Belas Kasih Allah, Mengungkapkan Wajah Belaskasih Allah" dalam Pastoral Keluarga", dalam Komisi Keluarga Konferensi Waligereja Indonesia, Keluarga (Bulletin Sarana dan Wahana Komunikasi Pastoral Keluarga), no. 1/Januari-April 2016, hlm. 23-41.

Leks, Stefan., "Kerahiman Allah, Intisari Hidup Gereja” dalam Hidup Katolik.com.

Lobo, Joseph., "Mercy and Justice: The Warp and Woof of Human Life" dalam Vidyajyoti Journal of Theological Reflection (VJTR) vol. 80/4/ April 2016, hlm. 27-46.

Meifung, Monica Maria., "Memaknai Tahun Kerahiman” dalam Rohani, no.2/LXI/Februari 2016, hlm. 11-14.

Pontifical Council for the Promotion of the New Evangelization, Mercy in the Fathers of the Church. United States of America: Promotion of the New Evangelization, 2015.

Poovathumkudy, Kuriakose, "Holy Year of Mercy: An Exploratory Study of Misericordiae Vultus" dalam Vidyajyoti Journal of Theological Reflection (VJTR) vol. 80/2/February 2016, hlm. 9-20.

Sindunata, Gabriel Possenti., "Bermurah hati terhadap anak" dalam Utusan, no. 07/LXVI/Juli 2016, hlm. 2-3. 
Sindunata, Gabriel Possenti., "Tergerak oleh Belas Kasih” dalam Utusan, no. 03/LXVI/Maret 2016, hlm. 2-3.

http://www.usccb.org/beliefs-and-teachings/how-we-teach/newevangelization/jubilee-of-mercy/frequently-asked-questionsabout-the-jubilee-of-mercy.cfm;

http://www.usccb.org/beliefs-and-teachings/how-we-teach/newevangelization/jubilee-of-mercy/frequently-asked-questionsabout-the-jubilee-of-mercy.cfm;

https:/ / cvcomment.org/2015/12/08/what-you-need-to-know-aboutthe-jubilee-of-mercy/

http://www.usccb.org/beliefs-and-teachings/how-we-teach/newevangelization/jubilee-of-mercy/frequently-asked-questionsabout-the-jubilee-of-mercy.cfm;

http://www.orlandodiocese.org/e-scroll/archive/ presentation-of-theextraordinary-jubilee-of-mercy-2/

https:/ / cvcomment.org/2015/12/08/what-you-need-to-know-aboutthe-jubilee-of-mercy/

http:/ / ncronline.org/news/vatican/proclaiming-jubilee-francisenvisions-non-judging-non-condemning-church

https://w2.vatican.va/content/francesco/en/audiences/2015/docume nts/papa-francesco_20151209_udienza-generale.html

http://www.americamagazine.org/content/dispatches/pope-francisannounces-jubilee-year-mercy

http://ncronline.org/news/vatican/francis-announces-new-globaljubilee-holy-year-mercy

http://www.orlandodiocese.org/e-scroll/archive/ presentation-of-theextraordinary-jubilee-of-mercy-2/

http:/ /archomaha.org/wpcontent/uploads/2015/11/FrequentlyAskedQuestionsRegarding the_Jubilee_of_Mercy.pdf 
Sihol Situmorang, Misericordiae Vultus

http:/ / www.im.va/content/gdm/en/giubileo/logo.html;

http://archomaha.org/wp-

content/uploads/2015/11/FrequentlyAskedQuestionsRegarding_ the_Jubilee_of_Mercy.pdf

https://w2.vatican.va/content/francesco/en/homilies/2015/document s/papa-francesco_20151208_giubileo-omelia-apertura.html. 